
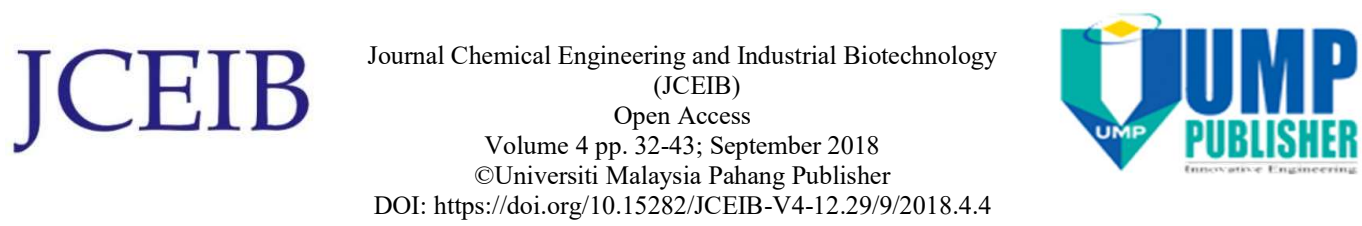

\title{
PEFORMANCE EVALUATION OF PETROCHEMICAL WASTEWATER FED AIR-CATHODE MICROBIAL FUEL CELLS USING YEAST BIOCATALYST
}

Sumaya Sarmin a, Asmida Binti Ideris a,, Chin Sim Yee a,, Chin Kui Cheng a,, Md. Maksudur Rahman Khan ${ }^{\text {a,* }}$

a Faculty of Chemical and Natural Resources Engineering, Universiti Malaysia Pahang, Lebuhraya Tun Razak, 26300 Gambang, Kuantan, Pahang, Malaysia

*E-mail: mrkhancep@yahoo.com

\begin{abstract}
This paper presents the performance of air-cathode microbial fuel cell (AC-MFC) treating the petrochemical wastewater (PCW) from acrylic acid plant. The wastewater which is typically incinerated and possesses very high chemical oxygen demand (COD) due to presence of acrylic acid along with other organic acids. The goal of the present study is to evaluate the viability of treating the wastewater using yeast (Saccharomyces cerevisiae) as biocatalyst in AC-MFC for simultaneous treatment of wastewater and electricity generation. This study demonstrates that Saccharomyces cerevisiae could function as a good biocatalyst producing high power density of $0.24 \mathrm{~W} / \mathrm{m}^{3}$ using PCW with an initial COD of $26,000 \mathrm{mg} / \mathrm{L}$. The COD removal efficiency and the columbic efficiency (CE) were found as $38 \%$ and $23.6 \%$ respectively. The electron transfer process across the electrode/biofilm/solution interface was analyzed by electrochemical impedance spectroscopy (EIS). The present work demonstrates the potential of MFC for the treatment of acrylic acid plant PCW using Saccharomyces cerevisiae as biocatalyst.
\end{abstract}

Keywords: AC-MFC, petrochemical wastewater, Saccharomyces cerevisiae, power generation and columbic efficiency

\subsection{INTRODUCTION}

The world is confronting with three major inter-connecting issues: energy crisis, environmental pollution, and the global warming (Ahmed \& Kim, 2011). Although huge efforts have been made in promoting the renewable energy sector, the petro-energy sector is still prominent. Additionally, petrochemical industries are growing very fast (Seers, 1964) generating huge amount of wastewater that causes environmental problem (Majumder et al., 2014). The major sources for wastewater are the petroleum refinery wastewater (PRW) and the petrochemical wastewater (PCW) from various petrochemical industries. Acrylic acid (AA) production plant is one of the representatives of the petrochemical plants. AA is considered as a hazardous compound and used for the production of acrylic resins, acrylic esters, flocculants and dispersants (Allison, Singh, Webb, \& Grant, 2011). Several industrial wastewater treatment technologies, such as physico-chemical treatment (Liang, Mai, Tang, \& Wei, 2018), biological treatment (Mohanakrishna, Abu-Reesh, \& Al-Raoush, 2018) and advanced oxidation processes (Coelho, Castro, Dezotti, \& Sant'Anna Jr, 2006) are currently available. Incineration is 
one of the widely used technologies to tackle the PCW problem but it is energy intensive and not environment friendly producing huge amount of greenhouse gases (Lahiere \& Goodboy, 1993). The conventional physico-chemical treatment methods produce a significant amount of solid waste (Bahri, Mahdavi, Mirzaei, Mansouri, \& Haghighat, 2018). Biological treatment of the wastewater is very promising as it requires less energy (Kleerebezem \& Macarie, 2003). The biological treatment with simultaneous production of electricity can be carried out in microbial fuel cell (MFC). MFC is a bioelectrochemical system which has the capability to recycle the environmental pollutants by utilizing the organic compounds of the wastewater using microbes as biocatalysts (Ahmed \& Kim, 2011; Md Amirul Islam, Khan, Yousuf, Wai, \& Cheng, 2016). In recent years, the MFC research has gained impetus attention as an alternative source of energy (Md Amirul Islam et al., 2016). Different types of MFCs have already been introduced such as single chamber, double chamber, membrane-less chamber etc. Among these, single chamber MFC configuration is preferred for the wastewater treatment due to low cost, simple structure and higher output. Besides, mass transfer loss can be reduced via the direct oxygen supply from air to the electrode (Cheng \& Logan, 2011).

Different types of wastewater such as Dairy wastewater (DW) (Boas et al., 2015), municipal wastewater (Rodrigo et al., 2007), palm oil mill effluent (POME) (Baranitharan, Khan, \& Prasad, 2013), petroleum refinery wastewater (PRW) (Majumder et al., 2014) and mineral refinery wastewater (MRW) (Addi et al., 2018) have already been used in MFC where different kind of microbes were used as biocatalyst. However, AA plant wastewater has never been used as substrate in MFC. The major requirement of the biocatalyst for using in MFC anode are: i) high growth rate in the wastewater; ii) ability to degrade the organics; iii) electrogenic property. Although, bacteria, pure or mixed cultures are extensively studied as biocatalyst in MFCs degrading complex wastewater, they might not be suitable for certain wastewater from petrochemical plants due to the presence of some toxicants. AA possesses toxic effects towards anaerobic bacteria, nevertheless it is reported to be adaptable to the anaerobic treatment (Speece, 1996). The viability of Saccharomyces cerevisiae cells in the chemical reagents is surprisingly great (White, 1953), hence can be considered as a potential biocatalyst for bio-electrochemical systems fed with PCW. In recent years, the yeast mediated MFCs showed good bio-catalytic activity for simultaneous degradation and power generation utilizing complex substrates (Pant et al., 2012). Yeast cultivated from $S$. cerevisiae is used as biocatalyst in glucose driven MFCs, however its catalytic activity has never been investigated in PCW from acrylic acid plant fed MFC. The goal of this paper is to evaluate the performance of Saccharomyces cerevisiae for simultaneous treatment and power generation from PCW. PCW with different concentrations has been used to evaluate the potentiality of the PCW in MFC. The electrochemical behaviour of yeast containing anode has also been investigated by using electrochemical impedance spectroscopy (EIS).

\subsection{Sample collection and preparation}

\subsection{MATERIALS AND METHODS}

Petrochemical wastewater (PCW) was collected from local acrylic acid plant. The PCW was filtered to remove the suspended particles and stored at $4{ }^{\circ} \mathrm{C}$ in refrigerator. The initial chemical oxygen demand (COD) and $\mathrm{pH}$ of $\mathrm{PCW}$ were found as $1,00,000 \mathrm{mg} / \mathrm{L}$ and 2.6 respectively. MFC anolyte was prepared by diluting the $\mathrm{PCW}$ with water to obtain 
initial COD values of 45,000, 26,000 and $15,000 \mathrm{mg} / \mathrm{L}$. The $\mathrm{pH}$ of the PCW was adjusted by $1 \mathrm{M} \mathrm{NaOH}$ solution.

\subsection{Inoculum collection and preparation}

Dried form of industrial Saccharomyces cerevisiae was used in this study. For inoculums preparation, $100 \mathrm{~mL}$ distilled water autoclaved at $121{ }^{\circ} \mathrm{C}$ for $15 \mathrm{~min}$ and subsequently cooled to room temperature. Thereafter, $0.5 \mathrm{wt} \%$ of $S$. cerevisiae was added with autoclaved water and incubated at $37^{\circ} \mathrm{C}, 150 \mathrm{rpm}$ for $48 \mathrm{~h}$.

\subsection{MFC operation}

Single chamber MFC using cubic plexi glass with a dimension of $(10 \times 10 \times 10 \mathrm{~cm})$ as shown in Figure 1 was used in this study. The polyacrylonitrile coated carbon felt (PACF) with a dimension of $(3 \times 3 \mathrm{~cm})$ and $40 \% \mathrm{MnO}_{2} /$ Carbon nanotube coated PACF were used as anode and cathode respectively. The anode electrode was treated with $\mathrm{NaOH}(1.0 \mathrm{M})$ solution followed by HCL (1.0 M) solution after each experiment and kept in distilled water. The anode and the cathode were separated by Nafion membrane (Nafion117, Dupont Co., Wilmington, DE). The membrane was treated using diluted $\mathrm{H}_{2} \mathrm{SO}_{4}$ and distilled water at $80^{\circ} \mathrm{C}$ for $1 \mathrm{~h}$ and thereafter it was washed for several times with distilled water. The treated membrane was soaked in distilled water for overnight before use. For the preparation of catalyst ink, $22 \mathrm{mg}$ of catalyst was dispersed in $0.15 \mathrm{~mL}$ of $5 \mathrm{wt} \%$ Nafion solution and $0.15 \mathrm{~mL}$ isopropanol by ultrasonication for $15 \mathrm{~min}$. The catalyst ink was coated onto the carbon felt (active area, $7 \mathrm{~cm}^{2}$ ) by brushing technique followed by drying at $60{ }^{\circ} \mathrm{C}$ (Khan \& Lin, 2006). The membrane-electrode-assembly (MEA) was prepared by hot pressing the catalyst coated carbon felt with the pre-treated Nafion membrane for $3 \mathrm{~min}$ at a press temperature and pressure of $100^{\circ} \mathrm{C}$ and $1 \mathrm{bar}$, respectively. The MEA was positioned at the front of the opening place of the cubic part by keeping the membrane side towards the anode substrate. Thereafter, the whole MFC setup was tightened with screws. The anode chamber was filled with PCW and purged with nitrogen for half hour and inoculated with $2 \mathrm{~mL}$ of Saccharomyces cerevisiae culture. The anode chamber was closed tightly. The anode and the cathode electrodes were connected by titanium wire with a rheostat (Crotech DRB-9, UK) to form an electrical circuit. The single chamber MFC was run for 9 days. 


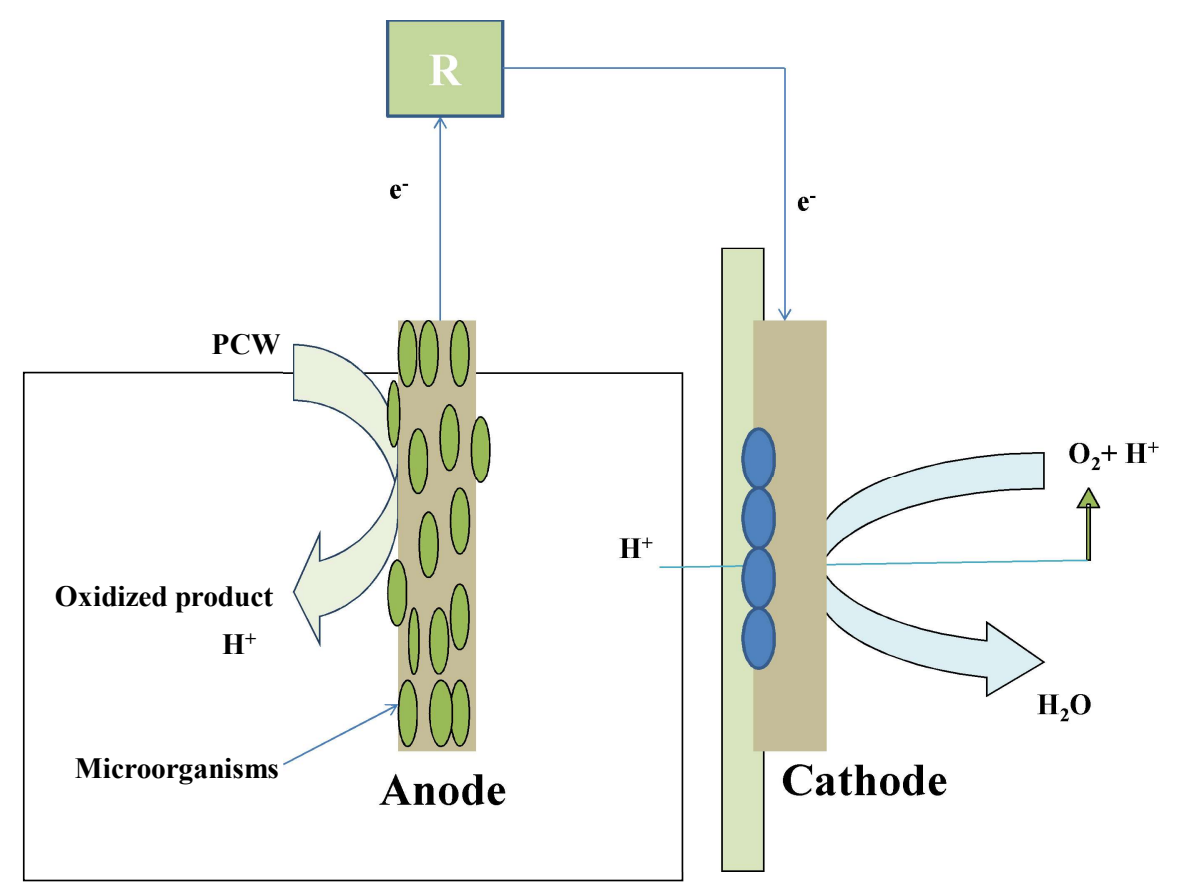

Figure 1: Schematic representation of AC-MFC

\subsection{Calculation}

The polarization curve was obtained with a resistance of 20-20000 $\Omega$ at regular time interval using True RMS multimeter, Fluke 289 with data logger. The power density was calculated by using the following equation:

$$
P=\frac{U I}{v}
$$

where, $\mathrm{P}$ is the power density $\left(\mathrm{W} / \mathrm{m}^{3}\right), \mathrm{U}$ is the voltage $(\mathrm{V}), \mathrm{I}$ is the current $(\mathrm{A})$ and $v$ is the total working volume of the anode chamber (L).

Liquid samples from anode chamber were collected by syringe for COD determination at every $48 \mathrm{~h}$ and the COD was measured by using a COD reactor (HACH DRB 200, Loveland, CO). To determine the COD removal efficiency $(\eta)$, the following equation was used (Baranitharan, Khan, Prasad, et al., 2015):

$$
\eta=\frac{C O D_{\text {initial }}-C O D_{\text {final }}}{C O D_{\text {initial }}} \times 100 \%
$$

where, $\mathrm{COD}_{\text {initial }}$ is the Initial COD of the substrate $(\mathrm{mg} / \mathrm{L})$ and $\mathrm{COD}_{\text {final }}$ is the final COD of the substrate $(\mathrm{mg} / \mathrm{L})$.

The columbic efficiency (CE) was calculated by the following equation (Baranitharan, Khan, Prasad, et al., 2015).

$$
C E=\frac{8 \int_{0}^{t} I d t}{F V \triangle C O D}
$$

where, I is the current (A), $t$ is the change in time (s), $F$ is the Faraday's constant $(96485$ $\mathrm{C} / \mathrm{mol}), \mathrm{V}$ is the volume of liquid in anode compartment (L), and $\triangle \mathrm{COD}$ is the change in COD concentration $(\mathrm{g} / \mathrm{L})$. 


\subsection{Electrochemical analysis}

EIS was employed to analyze the interfacial charge transfer resistances of the anode. EIS experiments were done by using potentiostat Metrohm autolab (Autolab Compact PGSTAT 204, Netherland). The anode and the cathode were used as working and counter electrode respectively. $\mathrm{Ag} / \mathrm{AgCl}(1.0 \mathrm{M} \mathrm{KCl})$ electrode was used as reference electrode and placed near to the working electrode using a lugging capillary. The system was run with a frequency range of $100 \mathrm{kHz}-5 \mathrm{mHz}$ and an AC signal with an amplitude of $10 \mathrm{mV}$.

\subsection{Time vs. current curve and the polarization curve}

\subsection{RESULTS AND DISCUSSION}

The MFCs were run at different concentrations of PCW with initial COD of 45,000 mg/L, $26,000 \mathrm{mg} / \mathrm{L}$ and $15,000 \mathrm{mg} / \mathrm{L}$. The typical current vs. time for PCW driven MFC with initial COD of 26,000 mg/L has been shown in Figure 2(a).
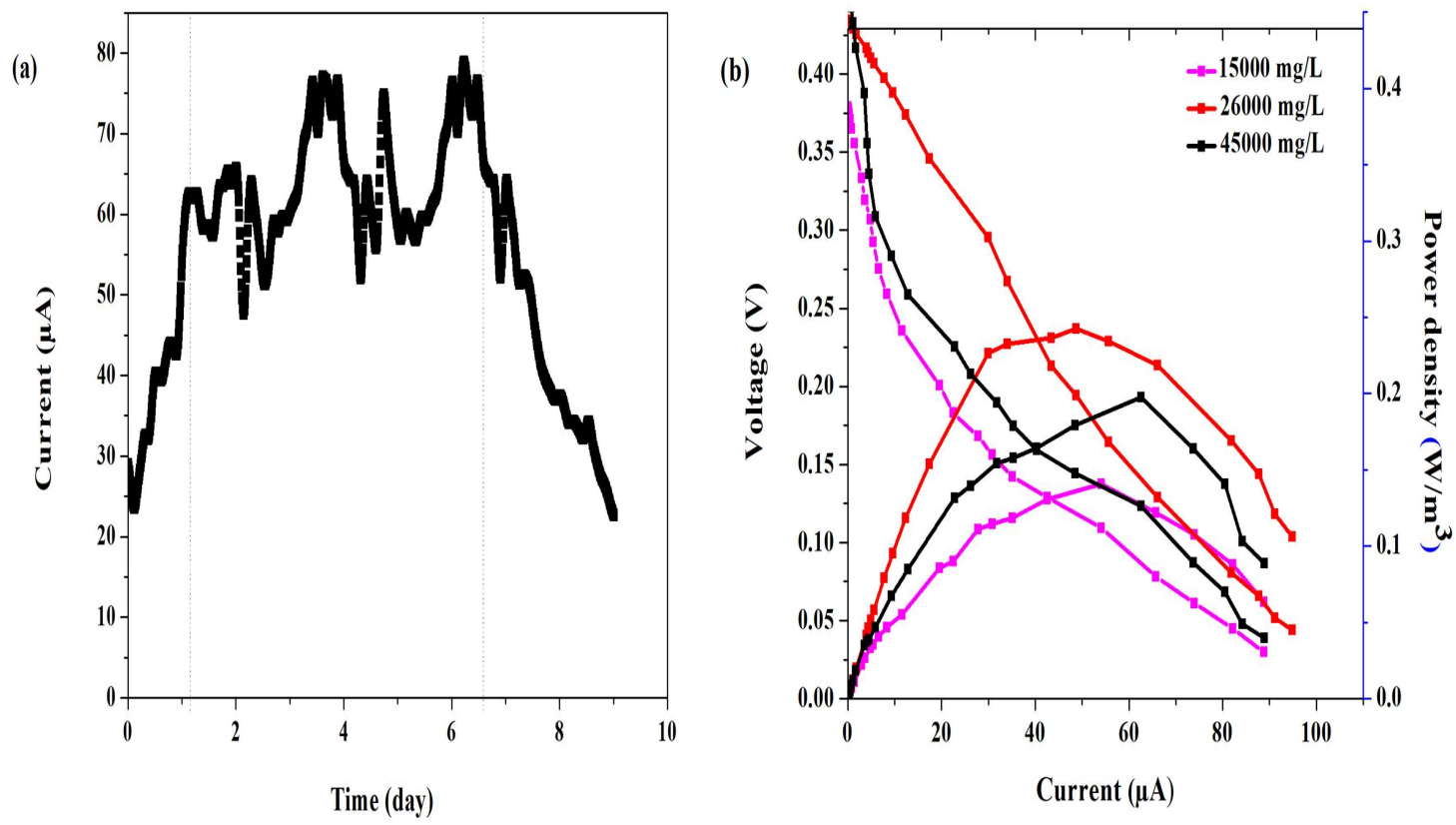

Figure 2: (a) Time vs. current curve [initial COD $=26,000 \mathrm{mg} / \mathrm{L}$; external resistance $=1$ $\mathrm{k} \Omega$ ] and (b) the polarization curve at different initial COD

From Figure 2(a), it can be seen that the electricity generation initially grows rapidly in $24 \mathrm{hr}$ of operation and reaches an apparent stable phase producing around $62 \pm 12 \mu \mathrm{A}$ current until 7 days of operation and thereafter, it drastically drops from $7^{\text {th }}$ to $9^{\text {th }}$ day of operation. The initial growth pattern is very similar to the decay pattern indicating that the growth of the microbes was initially very fast, however the presence of some toxicants may cause the inactivation of the yeast cells at later stage. The maximum power generation at different initial COD values was investigated by using polarization curve at 6 th day of operation and presented in Figure 2(b). The maximum power generation at initial COD of $15000 \mathrm{mg} / \mathrm{L}$ was $0.19 \mathrm{~W} / \mathrm{m}^{3}$ which was increased to $0.24 \mathrm{~W} / \mathrm{m}^{3}$ with the increase in initial COD to $26000 \mathrm{mg} / \mathrm{L}$ and with further increase in initial COD to 45000 $\mathrm{mg} / \mathrm{L}$, the maximum power generation was dropped significantly to $0.14 \mathrm{~W} / \mathrm{m}^{3}$. 


\subsection{Effect of COD removal efficiency with the power density}

The correlation of COD removal efficiency with the power density at $2^{\text {nd }}, 4^{\text {th }}$ and $6^{\text {th }}$ day of operation is presented in Figure 3:

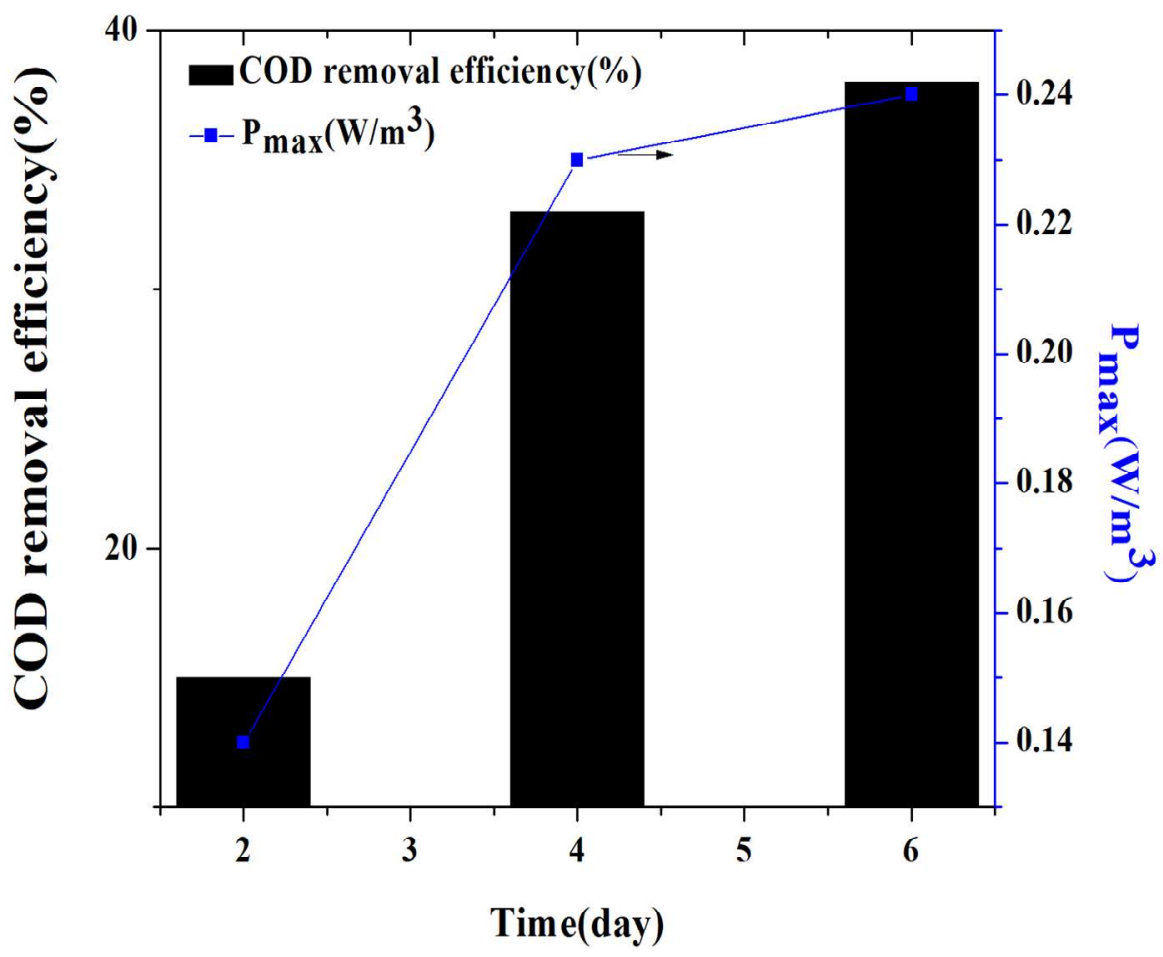

Figure 3: COD removal efficiency and maximum power density as a function of time [Initial COD $=26,000 \mathrm{mg} / \mathrm{L}$ ]

From the Figure 3, it can be seen the power generation increased drastically from $2^{\text {nd }}$ to $4^{\text {th }}$ day of operation and the COD removal efficiency was also increased in line with the power generation (Baranitharan, Khan, Yousuf, et al., 2015) suggesting that the yeast cell growth in the bulk solution as well as on the electrode surface concurrently occurred leading to the simultaneous power generation and COD removal. However, from $4^{\text {th }}$ to $6^{\text {th }}$ day of operation the increment rate of power generation was significantly lower than the COD removal. Power generation in MFCs mainly occurs in the biofilm (Franks, Malvankar, \& Nevin, 2010), whereas the COD removal occurs predominantly in the bulk solution. The stagnancy in the power generation from $4^{\text {th }}$ to $6^{\text {th }}$ day indicates the retardation of the biofilm activity possibly due to the accumulation of the toxicants (Aquino \& Stuckey, 2004). In the bulk the concentration of toxicants might be too low, and the yeast cells could survive leading to higher COD removal efficiency. The maximum power density, COD removal efficiency and CE in the present study have been compared with other literature and shown in Table 1.

Table 1: Performance comparison of MFC treatment of wastewater with the literature 


\begin{tabular}{|c|c|c|c|c|c|c|c|c|}
\hline $\begin{array}{l}\text { Types of } \\
\text { electrode }\end{array}$ & Inoculum & Chamber & Electrode & $\begin{array}{c}\text { Initial } \\
\text { COD } \\
(\mathrm{mg} / \mathrm{L})\end{array}$ & $\begin{array}{c}\text { Power } \\
\text { density } \\
\left(\mathrm{W} / \mathbf{m}^{3}\right)\end{array}$ & $\begin{array}{l}\text { CE } \\
(\%)\end{array}$ & $\begin{array}{c}\eta \\
(\%)\end{array}$ & Ref. \\
\hline$\overline{P C W}$ & $\begin{array}{c}S . \\
\text { cerevisiae }\end{array}$ & Single & $\begin{array}{c}\text { Carbon } \\
\text { felt }\end{array}$ & 26,000 & 0.24 & 23.58 & 38 & This study \\
\hline POME & $\begin{array}{l}\text { Anaerobic } \\
\text { sludge }\end{array}$ & Double & PACF & 60,000 & 0.309 & 0.8 & 45 & $\begin{array}{c}\text { (Baranitharan } \\
\text { et al., 2013) }\end{array}$ \\
\hline PRW & P. putida & Single & PTTE & 2,213 & 0.09 & 0.06 & 30 & $\begin{array}{c}\text { (Majumder et } \\
\text { al., 2014) }\end{array}$ \\
\hline MRW & $\begin{array}{l}\text { Anaerobic } \\
\text { sludge }\end{array}$ & Single & $\begin{array}{c}\text { Graphite } \\
\text { rod and } \\
\text { bar }\end{array}$ & 1,760 & 0.045 & 1.5 & 80 & $\begin{array}{c}\text { (Addi et al., } \\
\text { 2018) }\end{array}$ \\
\hline DW & $\begin{array}{c}L . \\
\text { pentosus }\end{array}$ & Double & Graphite & - & 0.02 & 2.08 & 56 & $\begin{array}{c}\text { (Boas et al., } \\
\text { 2015) }\end{array}$ \\
\hline
\end{tabular}

From Table 1, it can be seen that the PCW driven MFC with Saccharomyces cerevisiae as biocatalyst produced significantly higher power compared to PRW operating with $P$. putida, MRW using Anaerobic sludge and DW using L. pentosus. The POME driven MFC showed higher power generation where anaerobic sludge was used as biocatalyst. The chemical composition as well as the inoculum for these wastewaters are different. PCW from AA plant usually contains AA in a range of 4-15 wt.\% (Ahmad, Kamaruzzaman, \& Chin, 2014) where as PRW contains mainly phenolic compounds (Wagner \& Nicell, 2001). Hence the total number of electron produced by the decomposition of the substrate might be different. However, CE is measure of electrochemical efficiency of the biocatalyst normalized by the COD removal. The CE in the present study was significantly higher than the other studies indicating the superior bio-electrocatalytic property of $S$. cerevisiae. The $38 \%$ COD removal in the present study was obtained during 6 days of operation whereas for POME driven MFC (Baranitharan et al., 2013) 45\% COD was removed after 14 days of operation. The faster degradation of the PCW and higher CE indicate the potentiality of the $S$. cerevisiae for simultaneous treatment and power generation from AA plant wastewater.

\subsection{EIS analysis}

The anode interfacial characteristics have been investigated by EIS. The Bode plots and the Nyquist plot are presented in Figure 4(a) and 4(b). The measurement of EIS spectra of the anode provides the information about the processes occurring in the biofilm, electrode, the electrolyte and their interfaces. 

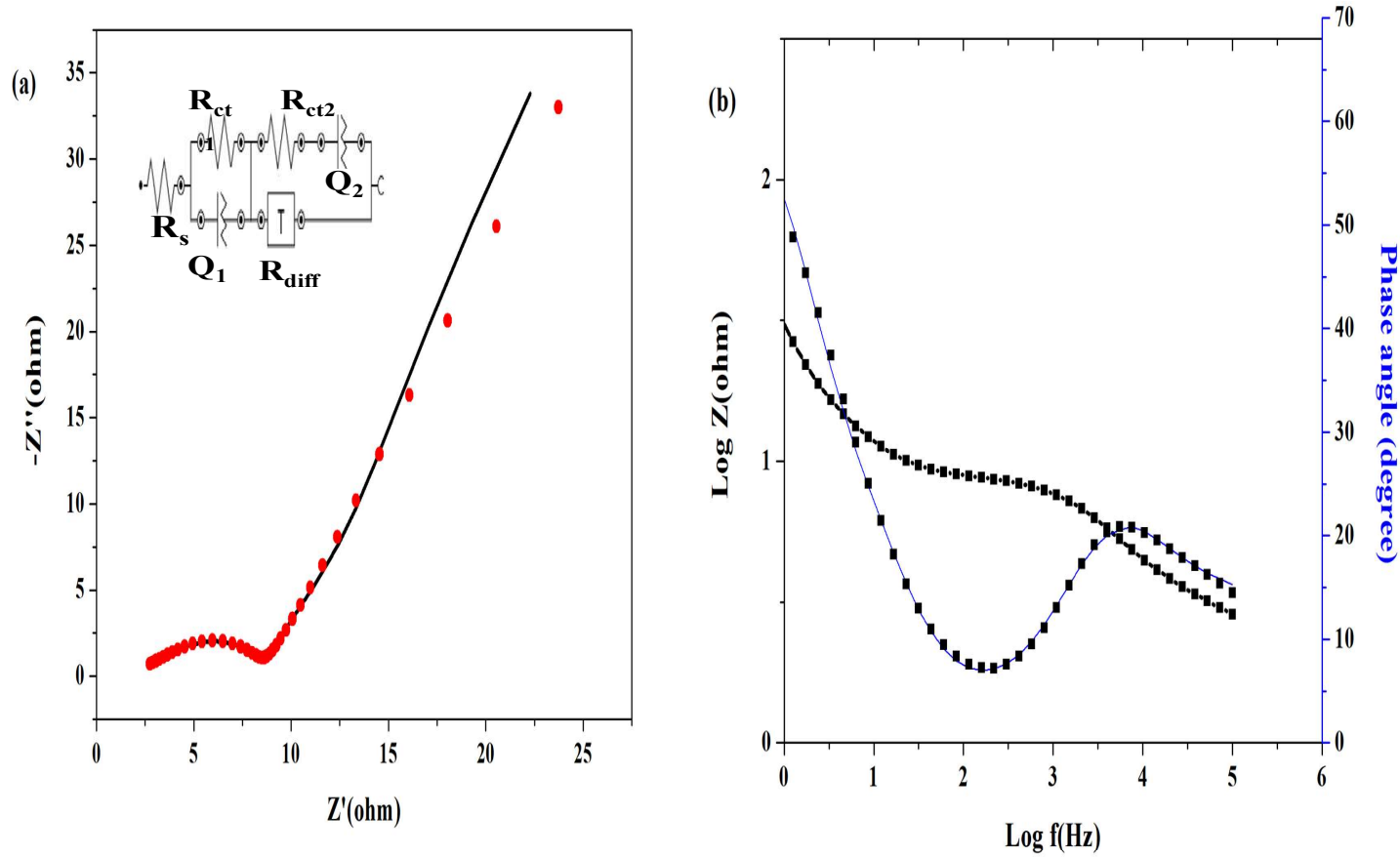

Figure 4: (a) Nyquist plot for anode of the MFC, and (b) the Bode plot [The dots are the experimental points and the line is obtained from EIS fitting; Initial COD $=26,000$ $\mathrm{mg} / \mathrm{L}$; Operation] time $=6^{\text {th }}$ day

Nyquist plot (figure 4a) represents a complex plane plot for the anode of the MFC expressing the real (X-axis) and imaginary part impedance (Y-axis) (He \& Mansfeld, 2009). The Nyquist plot formed a semicircle at higher frequency region followed by a tail at medium to lower frequency region. Typically, the high frequency impedance limit indicates the ohmic resistance $\left(\mathrm{R}_{\mathrm{s}}\right)$ and the diameter of the semicircle arc represents the charge transfer resistance $\left(\mathrm{R}_{\mathrm{ct}}\right)$ (ter Heijne, Liu, Sulonen, Sleutels, \& Fabregat-Santiago, 2018). Bode plot is presented in Figure 4(b) be representing the information of impedance, frequency and phase angle (He \& Mansfeld, 2009). The anode impedance data was fitted by an equivalent circuit $\left[R_{s}\left(R_{c t 1} Q_{1}\right)\left(\left[R_{c t 2} Q_{2}\right] T\right)\right]$, shown in the inset of Figure 4(a) which present the complex behaviour of the bio-electrochemical reactions. The components of the equivalent circuit $R_{s}, R_{c t 1}, R_{c t 2}, Q_{1}, Q_{2}$ and $T$ represent the ohmic resistance, charge transfer resistances $\left(R_{c t 1}\right.$ and $\left.R_{c t 2}\right)$, constant phase elements $\left(Q_{1}\right.$ and $\left.Q_{2}\right)$ and the tangent-hyperbolic respectively. The charge transfer resistance at the electrode/biofilm interface is represented by $\mathrm{R}_{\mathrm{ct} 1}$, whereas the charge transfer resistance across the biofilm/solution interface is represented by $\mathrm{R}_{\mathrm{ct} 2}$ (ter Heijne et al., 2018). The diffusion process can be characterized by diffusion resistance $\left(R_{d}\right)$ which is the portion of the real axis between the vertical capacitance line and the high-frequency tail of the semicircle surface(ter Heijne et al., 2018). $R_{d}$ is calculated by the following equation (Ruffo, Hong, Chan, Huggins, \& Cui, 2009).

$$
R_{d}=\frac{B}{3 Y_{0}}
$$

where, $\mathrm{B}$ is the admittance parameter and $\mathrm{Y}_{0}$ is the time constant are obtained from EIS fitting.

The resistances determined by the EIS data fitting with the equivalent circuit are presented in Table 2. 
Table 2: EIS data fitting parameters for AC-MFC

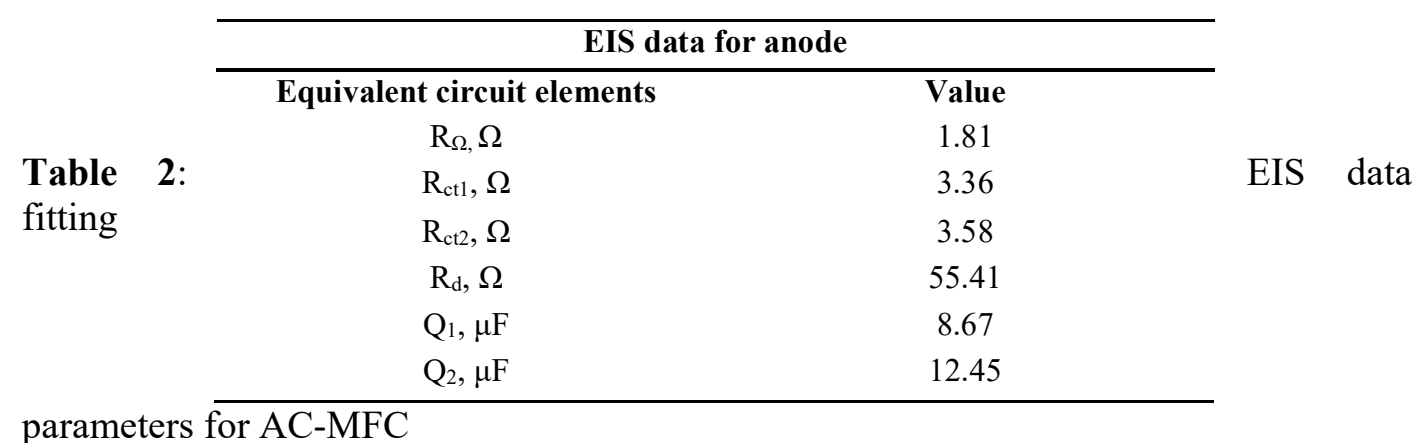

The charge transfer resistances $R_{\mathrm{ct} 1}$ was found slightly lower than the $R_{\mathrm{ct} 2}$ indicating a fast charge transfer between the yeast cells at biofilm as the electrode (ter Heijne et al., 2018). The mass transfer resistance was found to be significantly higher compared to the other resistances indicating poor diffusivity might be due to the higher diffusion path (M Amirul Islam, Ethiraj, Cheng, Yousuf, \& Khan, 2018). Further study should be done to reduce the mass transfer resistance in the MFC for the enhancement in the power generation. Additionally mixed inoculum can be developed enabling the concurrent degradation of the toxicants.

\subsection{CONCLUSIONS}

The present information study provides on PCW driven MFC operation that can be a way towards practical development of MFC technology for the treatment of PCW from AA plant. Bio-electricity generation using PCW was successfully done in an AC-MFC using Saccharomyces cerevisiae. The maximum columbic efficiency (CE) and the COD removal efficiency were $23.58 \%$ and $38 \%$ respectively after 6 days of operation using PCW with an initial COD of $26000 \mathrm{mg} / \mathrm{L}$. The results of the present work demonstrate the potentiality of MFC for the simultaneous treatment and bioelectricity generation using PCW.

\section{ACKNOWLEDGEMENT}

The authors are thankful to Universiti Malaysia Pahang (www.ump.edu.my) for providing research grant (RDU180355).

\section{REFERENCES}


Addi, H., Mateo-Ramírez, F., Ortiz-Martínez, V. M., Salar-García, M. J., HernándezFernández, F. J., Pérez de los Ríos, A., . . Blanco, L. J. L. (2018). Treatment of Mineral Oil Refinery Wastewater in Microbial Fuel Cells Using Ionic Liquid Based Separators. Applied Sciences, 8(3), 438.

Ahmad, M., Kamaruzzaman, M., \& Chin, S. (2014). New method for acrylic acid recovery from industrial waste water via esterification with 2-ethyl hexanol. Process Safety and Environmental Protection, 92(6), 522-531.

Ahmed, J., \& Kim, S. (2011). Effect of cathodic biofilm on the performance of aircathode single chamber microbial fuel cells. Bulletin of the Korean Chemical Society, 32(10), 3726-3729.

Allison, M., Singh, K., Webb, J., \& Grant, S. (2011). Treatment of acrylic acid production wastewater using a submerged anaerobic membrane bioreactor. Proceedings of the Water Environment Federation, 2011 (8), 6554-6564.

Aquino, S. F., \& Stuckey, D. C. (2004). Soluble microbial products formation in anaerobic chemostats in the presence of toxic compounds. Water research, 38(2), 255-266.

Bahri, M., Mahdavi, A., Mirzaei, A., Mansouri, A., \& Haghighat, F. (2018). Integrated oxidation process and biological treatment for highly concentrated petrochemical effluents: A review. Chemical Engineering and ProcessingProcess Intensification.

Baranitharan, E., Khan, M. R., \& Prasad, D. (2013). Treatment of palm oil mill effluent in microbial fuel cell using polyacrylonitrile carbon felt as electrode. Journal of Medical and Bioengineering Vol, 2(4).

Baranitharan, E., Khan, M. R., Prasad, D., Teo, W. F. A., Tan, G. Y. A., \& Jose, R. (2015). Effect of biofilm formation on the performance of microbial fuel cell for the treatment of palm oil mill effluent. Bioprocess and biosystems engineering, $38(1), 15-24$.

Baranitharan, E., Khan, M. R., Yousuf, A., Teo, W. F. A., Tan, G. Y. A., \& Cheng, C. K. (2015). Enhanced power generation using controlled inoculum from palm oil mill effluent fed microbial fuel cell. Fuel, 143, 72-79.

Boas, J. V., Oliveira, V., Marcon, L., Pinto, D., Simões, M., \& Pinto, A. (2015). Effect of operating and design parameters on the performance of a microbial fuel cell with Lactobacillus pentosus. Biochemical engineering journal, 104, 34-40.

Cheng, S., \& Logan, B. E. (2011). Increasing power generation for scaling up singlechamber air cathode microbial fuel cells. Bioresource technology, 102(6), 44684473.

Coelho, A., Castro, A. V., Dezotti, M., \& Sant'Anna Jr, G. (2006). Treatment of petroleum refinery sourwater by advanced oxidation processes. Journal of hazardous materials, 137(1), 178-184.

Franks, A. E., Malvankar, N., \& Nevin, K. P. (2010). Bacterial biofilms: the powerhouse of a microbial fuel cell. Biofuels, 1(4), 589-604.

He, Z., \& Mansfeld, F. (2009). Exploring the use of electrochemical impedance spectroscopy (EIS) in microbial fuel cell studies. Energy \& Environmental Science, 2(2), 215-219.

Islam, M. A., Ethiraj, B., Cheng, C. K., Yousuf, A., \& Khan, M. M. R. (2018). An Insight of Synergy between Pseudomonas aeruginosa and Klebsiella variicola in a Microbial Fuel Cell. ACS Sustainable Chemistry \& Engineering, 6(3), 41304137. 
Islam, M. A., Khan, M. R., Yousuf, A., Wai, W. C., \& Cheng, C. K. (2016). Electricity generation form pretreated palm oil mill effluent using Klebsiella Variicola as an inoculum in Microbial fuel cell. Paper presented at the Development in the in Renewable Energy Technology (ICDRET), 2016 4th International Conference on the.

Khan, M. R., \& Lin, S. D. (2006). Using Pt sols to prepare low Pt-loading electrodes for polymer electrolyte fuel cells. Journal of Power Sources, 162(1), 186-191.

Kleerebezem, R., \& Macarie, H. (2003). Treating industrial wastewater: anaerobic digestion comes of age: anaerobic treatment systems offer important advantages over conventionally applied aerobic processes for removing organic pollutants from water-based streams.(Cover Story). Chemical Engineering, 110(4), 56-65.

Lahiere, R. J., \& Goodboy, K. P. (1993). Ceramic membrane treatment of petrochemical wastewater. Environmental progress, 12(2), 86-96.

Liang, J., Mai, W., Tang, J., \& Wei, Y. (2018). Highly Effective Treatment of Petrochemical Wastewater by a Super-sized Industrial Scale Plant with Expanded Granular Sludge Bed Bioreactor and Aerobic Activated Sludge. Chemical Engineering Journal.

Majumder, D., Maity, J. P., Tseng, M.-J., Nimje, V. R., Chen, H.-R., Chen, C.-C., . . . Chen, C.-Y. (2014). Electricity generation and wastewater treatment of oil refinery in microbial fuel cells using Pseudomonas putida. International journal of molecular sciences, 15(9), 16772-16786.

Mohanakrishna, G., Abu-Reesh, I. M., \& Al-Raoush, R. I. (2018). Biological anodic oxidation and cathodic reduction reactions for improved bioelectrochemical treatment of petroleum refinery wastewater. Journal of Cleaner Production, 190, 44-52.

Pant, D., Singh, A., Van Bogaert, G., Olsen, S. I., Nigam, P. S., Diels, L., \& Vanbroekhoven, K. (2012). Bioelectrochemical systems (BES) for sustainable energy production and product recovery from organic wastes and industrial wastewaters. Rsc Advances, 2(4), 1248-1263.

Rodrigo, M., Canizares, P., Lobato, J., Paz, R., Sáez, C., \& Linares, J. (2007). Production of electricity from the treatment of urban waste water using a microbial fuel cell. Journal of Power Sources, 169(1), 198-204.

Ruffo, R., Hong, S. S., Chan, C. K., Huggins, R. A., \& Cui, Y. (2009). Impedance analysis of silicon nanowire lithium ion battery anodes. The Journal of Physical Chemistry C, 113(26), 11390-11398.

Seers, D. (1964). The mechanism of an open petroleum economy. Social and economic studies, 233-242.

Speece, R. E. (1996). Anaerobic biotechnology for industrial wastewaters Anaerobic biotechnology for industrial wastewaters.

ter Heijne, A., Liu, D., Sulonen, M., Sleutels, T., \& Fabregat-Santiago, F. (2018). Quantification of bio-anode capacitance in bioelectrochemical systems using Electrochemical Impedance Spectroscopy. Journal of Power Sources, 400, 533538.

Wagner, M., \& Nicell, J. (2001). Peroxidase-catalyzed removal of phenols from a petroleum refinery wastewater. Water Science and technology, 43(2), 253-260.

White, J. (1953). Effects of common bactericidal substances and of heat on yeast growth and viability. Journal of the Institute of Brewing, 59(6), 470-479. 